\title{
DETERMINING THE LENGMUR COEFFICIENT OF THE FILTRATION PROBLEM
}

\author{
Liudmila I. Kuzmina ${ }^{1}$, Yuri V. Osipov ${ }^{2}$ \\ ${ }^{1}$ National Research University Higher School of Economics, Moscow, RUSSIA \\ ${ }^{2}$ National Research Moscow State University of Civil Engineering, Moscow, RUSSIA
}

\begin{abstract}
Filtration of suspension in a porous medium is actual in the construction of tunnels and underground structures. A model of deep bed filtration with size-exclusion mechanism of particle capture is considered. The inverse filtration problem - finding the Langmuir coefficient from a given concentration of suspended particles at the porous medium outlet is solved using the asymptotic solution near the concentrations front. The Langmuir coefficient constants are obtained by the least squares method from the condition of best approximation of the asymptotics to exact solution. It is shown that the calculated parameters are close to the coefficients of the model, and the asymptotics well approximates the exact solution.
\end{abstract}

Keywords: deep bed filtration, porous medium, mathematical model, asymptotics, inverse problem

\section{О НАХОЖДЕНИИ КОЭФФИЦИЕНТА ЛЕНГМЮРА ЗАДАЧИ ФИЛЬТРАЦИИ}

\author{
Л.И. Кузьмина ${ }^{1}$, Ю.В. Осипов ${ }^{2}$ \\ ${ }^{1}$ Национальный исследовательский университет «Высшая школа экономики», г. Москва, РОССИЯ \\ ${ }^{2}$ Национальный исследовательский Московский государственный строительный университет, \\ г. Москва, РОССИЯ
}

\begin{abstract}
Аннотация: Задачи фильтрации суспензии в пористой среде актуальны при строительства туннелей и подземных сооружений. Рассматривается модель долговременной глубинной фильтрации с размерным механизмом задержания частиц. На основе асимптотики вблизи фронта концентраций взвешенных и осажденных частиц решается обратная задача фильтрации - нахождение коэффициента Ленгмюра по заданной концентрации взвешенных частиц на выходе пористой среды. Константы коэффициентов Ленгмюра находятся методом наименьших квадратов из условия наилучшего приближения асимптотики к точному решению. Показано, что вычисленные параметры близки к коэффициентам модели, а найденная асимптотика хорошо приближает точное решение.
\end{abstract}

Ключевые слова: долговременная глубинная фильтрация, пористая среда, математическая модель, асимптотика, обратная задача

\section{INTRODUCTION}

Transport and retention of solid particles in a porous medium occur in various natural phenomena and in industrial technologies. During the construction of tunnels and underground structures to create waterproof partitions, liquid concrete is pumped into the rock. The solution spreads through the pores and when solidified, forms a waterproof wall [1].
The transport of suspensions and colloids in porous media is accompanied by the retention of particles, which get stuck in the pores and form a deposit. The reasons for particle retention in porous media are straining, attachment, bridging, diffusion into dead-end pores, etc. [2, 3]. The intensity of various particle capture mechanisms depends on the physical and chemical properties of the particles, carrier fluid, and porous rock. If the particle and pore size distributions overlap, the predominant 
cause of retention is the blocking of large particles in small pores. This capture mechanism is called size-exclusion [4]. It is assumed that the retained particles cannot be knocked out of the pore throat by the fluid flow or suspended particles and always remain stationary.

The mathematical model of filtration includes the equation of mass balance of suspended and retained particles and the kinetic equation of deposit growth [5]. At low concentrations of suspended particles, the deposit growth rate is proportional to the first degree of suspended particles concentration. The proportionality coefficient depends on the concentration of the retained particles and is called the filtration function.

Mathematical models often have analytical solutions. For some problems, it is possible to obtain a global or local exact solution; in other cases, the asymptotics is constructed [69]. Analytical solutions allow to compare the mathematical model with the experiment and determine the parameters of the model from experimental data. The inverse filtration problem is to obtain the filtration function by the known concentration of suspended particles at the outlet of the porous medium, which can be measured in the laboratory.

For a simple filtration model that does not take into account the change in porosity during deposit growth, the inverse problem was solved in [10-12] by the method of successive approximations. The solution is based on Riemann relation between the concentrations of suspended and retained particles inside a porous medium at an arbitrary time moment with the concentrations at the porous medium inlet. However, this method is not applicable for complex filtration models in which several equation coefficients are functions of the concentrations of suspended and retained particles. In this article a new asymptotic method for solving the inverse filtering problem is proposed. Asymptotic formulas defining a solution to the filtration problem depend on the model parameters in explicit form. Equating the asymptotics to the given solution at the output of the porous medium, all the parameters of the model are determined.
In the simplest filtration model, the filtration function is a linear non-negative decreasing function of the retained particles concentration. Such a filtration function, called the Langmuir coefficient, is often used in mathematical models [13, 14]. Below, the asymptotic method for solving the filtration problem is used to obtain the parameters $\lambda_{0}, \lambda_{1}$ of the Langmuir coefficient.

\section{MATHEMATICAL MODEL}

The one-dimensional model of suspension and colloid filtration in a porous medium is defined by a system of partial differential equations of the first order with unknown concentrations of suspended $C(x, t)$ and retained $S(x, t)$ particles

$$
\begin{gathered}
\frac{\partial(C+S)}{\partial t}+\frac{\partial C}{\partial x}=0 ; \\
\frac{\partial S}{\partial t}=\Lambda(S) C .
\end{gathered}
$$

Here the filtration function $\Lambda(S)$ is a continuous positive decreasing function.

The dimensionless system of equations (1), (2) is considered in the domain

$$
\Omega=\{0 \leq x \leq 1, t \geq 0\} .
$$

The boundary conditions for system (1), (2) are set at the inlet of the porous medium $x=0$ and at the initial time $t=0$ :

$$
\begin{aligned}
& \left.C(x, t)\right|_{x=0}=1 ; \\
& \left.C(x, t)\right|_{t=0}=0 ; \\
& \left.S(x, t)\right|_{t=0}=0 .
\end{aligned}
$$

At the initial moment $t=0$, the porous medium does not contain any suspended and retained particles. The concentrations front of suspended and retained particles $t=x$ moves from the porous medium inlet $x=0$ to the outlet $x=1$ at a speed $v=1$. Before the front in the domain $\Omega_{0}=\{0 \leq x$ $\leq 1, t<x\}$, the porous medium is empty and the 
problem has a zero solution $C(x, t)=0 ; S(x, t)=0$. Behind the front in the domain

$$
\Omega_{S}=\{0 \leq x \leq 1, t>x\}
$$

a suspension and retained particles are present; the solution is positive $C(x, t)>0 ; S(x, t)>0$. At the concentration front, the solution $S(x, t)$ is continuous, the solution $C(x, t)$ has a gap.

A filtration function $\Lambda(S)$ that has a positive root is called a blocking filtration function. The most commonly used filtration function is the Langmuir coefficient [15]

$$
\Lambda(S)=\lambda_{0}-\lambda_{1} S, \lambda_{0}>0, \lambda_{1}>0 .
$$

In a domain $\Omega_{S}$ the problem (1)-(5) with Langmuir coefficient (6) has exact solution in explicit form [13]

$$
C_{e x}=\frac{e^{\lambda_{1}(t-x)}}{e^{\lambda_{1}(t-x)}+e^{\lambda_{0} x}-1}
$$

In the vicinity of the concentration front $t=x$, the second-order asymptotic solution to problem (1)-(6) has the form [16]

$$
\begin{aligned}
& C_{a s}=e^{-\lambda_{0} x}+\lambda_{1}\left(e^{-\lambda_{0} x}-e^{-2 \lambda_{0} x}\right)(t-x) \\
& +\lambda_{1}^{2}\left(2 e^{-3 \lambda_{0} x}-3 e^{-2 \lambda_{0} x}+e^{-\lambda_{0} x}\right)(t-x)^{2} / 2 .
\end{aligned}
$$

\section{INVERSE PROBLEM}

Suspended particles appear at the porous medium outlet at the moment $t=1$ because the length of the porous medium sample $l=1$ and the concentration front moves with speed $v=1$. The inverse problem is to obtain the filtration function $\Lambda(S)$ by the known suspended particles concentration $C(1, t)$ at the outlet of the porous medium.

Denote $\tau=t-1$.

Exact and asymptotic solutions of the suspended particles concentration at the outlet of the porous medium are obtained by substituting $x=1$ in formulas (7), (8)

$$
\begin{gathered}
C_{e x}(1, \tau)=\frac{e^{\lambda_{1} \tau}}{e^{\lambda_{1} \tau}+e^{\lambda_{0} x}-1} \\
C_{a s}(1, \tau)=e^{-\lambda_{0}}+\lambda_{1}\left(e^{-\lambda_{0}}-e^{-2 \lambda_{0}}\right) \tau \\
+\lambda_{1}^{2}\left(2 e^{-3 \lambda_{0}}-3 e^{-2 \lambda_{0}}+e^{-\lambda_{0}}\right) \tau^{2} / 2
\end{gathered}
$$

In the laboratory of the Australian School of Petroleum \& Energy Resources of the University of Adelaide, Australia, experiments were carried out to filter the suspension in a porous medium $[17,18]$. Chemical composition and size of the particles were selected so that size-exclusion was the main particle capture mechanism. According to the experiments, the parameters $\Lambda_{0}, \Lambda_{1}$ of the Langmuir coefficients $\Lambda(S)=\Lambda_{0}-$ $\Lambda_{1} S$ were obtained for filtration of monodisperse suspensions with solid particles of three sizes (see Table 1).

Table 1. Experimental Langmuir coefficients

\begin{tabular}{|c|c|c|}
\hline $\begin{array}{c}\text { Particle radius } \\
r_{n}, \mu\end{array}$ & $\Lambda_{0}$ & $\Lambda_{1}$ \\
\hline$r_{1}=1.568$ & 0,11 & 0,01351 \\
\hline$r_{2}=2.179$ & 0,59 & 0,005956 \\
\hline$r_{1}=3.168$ & 1,551 & 0,003457 \\
\hline
\end{tabular}

The unknown constants $\lambda_{0}, \lambda_{1}$ in the Langmuir coefficient (6) are determined by comparing the exact solution $C_{e x}(1, \tau)$ at the porous medium outlet of problem (1)-(5) calculated for the Langmuir coefficients given in Table 1 with the asymptotics (8). The constant $\lambda_{0}$ is determined by the suspended particles concentration at the time of the appearance of the suspension at the outlet of the porous medium (so called break-through concentration)

$$
\begin{array}{cl}
\tau=0: & C_{a s}(1,0)=e^{-\lambda_{0}}=C_{e x}(1,0) \\
& \Rightarrow \lambda_{0}=-\ln C_{e x}(1,0) .
\end{array}
$$

The constant $\lambda_{1}$ is obtained from the condition of the best approximation of the asymptotics to the exact solution by the least squares method on the interval $\tau \in[0 ; 10]$. 


\section{NUMERICAL CALCULATION}

To find the constant $\lambda_{1}$, the integral of the square of the difference between the exact and asymptotic solutions with the variable parameter $\lambda_{1}$ over the interval $\tau \in[0 ; 10]$ in the explicit form was calculated. The derivative of the integral with respect to the variable $\lambda_{1}$ is a third-order polynomial. The polynomial has 3 real roots for all three types of particles. Real polynomial root closest to the experimental constant $\Lambda_{1}$ is the desired approximation of the constant $\lambda_{1}$.

The results of calculating the constants $\lambda_{0}, \lambda_{1}$ are presented in Table 2.

Table 2. Experimental \& calculated constants

\begin{tabular}{|c|c|c|c|c|}
\hline$r_{n}, \mu$ & $\Lambda_{0}$ & $\lambda_{0}$ & $\Lambda_{1}$ & $\lambda_{1}$ \\
\hline$r_{1}=1.568$ & 0,11 & 0,11 & 0,01351 & 0,01352 \\
\hline$r_{2}=2.179$ & 0,51 & 0,51 & 0,005956 & 0,005955 \\
\hline$r_{3}=3.168$ & 1,551 & 1,551 & 0,003467 & 0,003467 \\
\hline
\end{tabular}

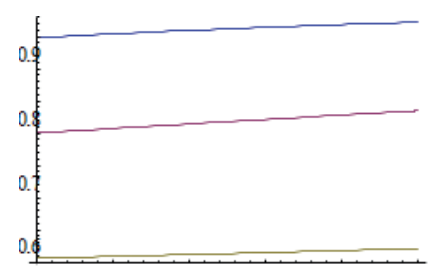

0.5

0.4

0.3

\section{$\begin{array}{llllll}0 & 10 & 20 & 30 & 40 & 50\end{array}$}

Figure 1. Suspended particles concentrations of 3 particle sizes at the outlet $x=1$
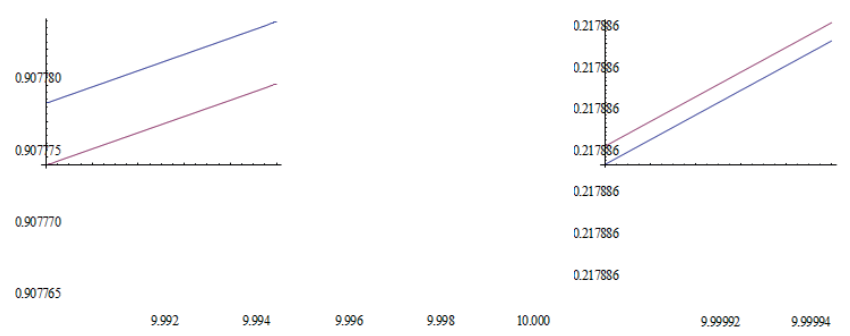

Figure. 2. Graph sections of the suspended particles concentrations at the porous medium outlet

According to Table 2, the relative error in finding the constants is less then $0.01 \%$; the error decreases with increasing particle radius.

Figure 1 shows the suspended particles concentrations of three particle sizes at the porous medium outlet: 1 - blue, 2 - red, 3 - brown. At $t$ $\leq 50$ the graphs of exact solution and asymptotics coincide for all three types of particles.

The graph sections with high resolution are shown in Figure 2 (the exact solution is blue, the asymptotics is red).

According to Figure $2 \mathrm{a}$ ), b), c) at time $t \leq 10$, the relative error of the asymptotics regarding exact solution is less than $0.001 \%$ for all types of particles.

\section{CONCLUSION}

An asymptotic method for solving the inverse filtering problem is studied. For example, the constants of the Langmuir coefficients are found. The parameters of the mathematical model are determined by comparing the exact solution with the asymptotics at the porous medium output.

It is shown that the least squares method is an effective way to obtain the model parameters. The coefficients of the filtration function are determined with an accuracy of $0.01 \%$; when $t \leq 10$ the asymptotics differs from the exact solution less than $0.001 \%$.

In the laboratory, the parameters of the mathematical model should be determined by measuring the concentration of suspended particles at the porous medium outlet [19]. In this case, the accuracy of finding the coefficients may deteriorate due to errors in laboratory measurements and deviations of the mathematical model from experimental conditions.

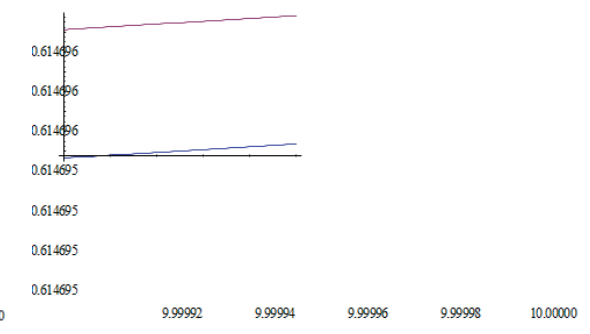


The next step in solving the inverse filtration problem is to obtain an unknown nonlinear filtration function that depends on 3 or more constants. In this case, problem (1)-(5) does not have an exact solution in explicit form. To solve the inverse problem, a numerical solution by the finite difference method is required $[20,21]$.

\section{REFERENCES}

1. Strømsvik H. The significance of hydraulic jacking for grout consumption during high pressure pre-grouting in Norwegian tunnelling. // Tunnelling and Underground Space Technology, 2019, vol. 90, pp. 357-368.

2. Civan F. Reservoir formation damage, third ed. Gulf Professional Publishing, Burlington, MA, USA, 2014.

3. Mays D.C., Hunt J.R. Hydrodynamic and chemical factors in clogging by montmorillonite in porous media. // Environmental Science and Technology, 2007, vol. 41, pp. 5666-5671.

4. Santos A., Bedrikovetsky P., Fontoura S. Analytical micro model for size exclusion: Pore blocking and permeability reduction. // Journal of Membrane Science, 2008, vol. 308, pp 115-127.

5. Herzig J.P., Leclerc D.M., Legoff P. Flow of suspensions through porous media application to deep filtration. // Industrial and Engineering Chemistry, 1970, vol. 62(5), pp. 8-35.

6. Kuzmina L.I., Osipov Yu.V., Vetoshkin N.V. Calculation of long-term filtration in a porous medium. // International Journal for Computational Civil and Structural Engineering, 2018, vol. 14(1), pp. 92-101.

7. Kuzmina L.I., Osipov Y.V., Zheglova Y.G. Modelling uniform asymptotics of the filtration problem in a porous medium. // IOP Conference Series: Materials Science and Engineering, 2018, vol. 456, 012051.

8. Kuzmina L.I., Osipov Yu.V., Zheglova Yu.G. Global asymptotics of the filtration problem in a porous medium. // International
Journal for Computational Civil and Structural Engineering, 2019, vol. 15(2), pp. 77-85.

9. Kuzmina L.I., Nazaikinskii V.E., Osipov Yu.V. On a deep bed filtration problem with finite blocking time. // Russian Journal of Mathematical Physics, 2019, vol. 26(1), pp. 130-134.

10. Alvarez A.C., Bedrikovetsky P.G., Hime G., Marchesin A.O., Marchesin D., Rodrigues J.R. A fast inverse solver for the filtration function for flow of water with particles in porous media. // Inverse Problems, 2006, vol. 22, pp. 69-88.

11. Alvarez A.C., Hime G., Marchesin D., Bedrikovetsky P.G. The inverse problem of determining the filtration function and permeability reduction in flow of water with particles in porous media. // Transport in Porous Media, 2007, vol. 70(1), pp. 43-62.

12. Alvarez A.C., Hime G., Silva J.D., Marchesin D. Analytic regularization of an inverse filtration problem in porous media. // Inverse Problems, 2013, vol. 29, 025006.

13. Vyazmina E.A., Bedrikovetskii P.G., Polyanin A.D. New classes of exact solutions to nonlinear sets of equations in the theory of filtration and convective mass transfer. // Theoretical Foundations of Chemical Engineering, 2007, vol. 41(5), pp. 556-564.

14. Malgaresi G., Collins B., Alvaro P., Bedrikovetsky P. Explaining non-monotonic retention profiles during flow of sizedistributed colloids. // Chemical Engineering Journal, 2019, vol. 375, 121984.

15. Altoe J.E., Bedrikovetsky P., Siqueira A.G., de Souza A.L.S., Shecaira F.S. Correction of basic equations for deep bed filtration with dispersion. // Journal of Petroleum Science and Engineering, 2006, vol. 51, pp. 68- 84.

16. Osipov Yu., Kotov N. Asymptotic model of size-exclusion grouting. // IOP Conference Series: Materials Science and Engineering, 2018, vol. 365, 042006.

17. Oliveira P., Vaz A., Siqueira F., Yang Y., You Z. Slow migration of mobilised fines during flow in reservoir rocks: Laboratory 
study. // Journal of Petroleum Science and Engineering, 2014, vol. 122, pp. 534-541.

18. Aji K., You Z., Badalyan A. Transport and straining of suspensions in porous media: experimental and theoretical study. // Thermal Science, 2012, vol. 16(5), pp. 1344-1348.

19. Badalyan A., You Z., Aji K., Bedrikovetsky P., Carageorgos T., Zeinijahromi A. Size exclusion deep bed filtration: Experimental and modelling uncertainties. // Review of scientific instruments, 2014, vol. 85(1), 015111.

20. Galaguz Y.P. Realization of the TVDscheme for a numerical solution of the filtration problem. // International Journal for Computational Civil and Structural Engineering, 2017, vol. 13(2), pp. 93-102.

21. Galaguz Y.P., Safina G.L. Modeling of fine migration in a porous medium. // MATEC Web of Conferences, 2016, vol. 86, 03003.

\section{СПИСОК ЛИТЕРАТУРЫ}

1. Strømsvik H. The significance of hydraulic jacking for grout consumption during high pressure pre-grouting in Norwegian tunnelling. // Tunnelling and Underground Space Technology, 2019, vol. 90, pp. 357-368.

2. Civan F. Reservoir formation damage, third ed. Gulf Professional Publishing, Burlington, MA, USA, 2014.

3. Mays D.C., Hunt J.R. Hydrodynamic and chemical factors in clogging by montmorillonite in porous media. // Environmental Science and Technology, 2007, vol. 41, pp. 5666-5671.

4. Santos A., Bedrikovetsky P., Fontoura S. Analytical micro model for size exclusion: Pore blocking and permeability reduction. // Journal of Membrane Science, 2008, vol. 308, pp 115-127.

5. Herzig J.P., Leclerc D.M., Legoff P. Flow of suspensions through porous media application to deep filtration. // Industrial and Engineering Chemistry, 1970, vol. 62(5), pp. 8-35.
6. Kuzmina L.I., Osipov Yu.V., Vetoshkin N.V. Calculation of long-term filtration in a porous medium. // International Journal for Computational Civil and Structural Engineering, 2018, vol. 14(1), pp. 92-101.

7. Kuzmina L.I., Osipov Y.V., Zheglova Y.G. Modelling uniform asymptotics of the filtration problem in a porous medium. // IOP Conference Series: Materials Science and Engineering, 2018, vol. 456, 012051.

8. Kuzmina L.I., Osipov Yu.V., Zheglova Yu.G. Global asymptotics of the filtration problem in a porous medium. // International Journal for Computational Civil and Structural Engineering, 2019, vol. 15(2), pp. 77-85.

9. Kuzmina L.I., Nazaikinskii V.E., Osipov Yu.V. On a deep bed filtration problem with finite blocking time. // Russian Journal of Mathematical Physics, 2019, vol. 26(1), pp. 130-134.

10. Alvarez A.C., Bedrikovetsky P.G., Hime G., Marchesin A.O., Marchesin D., Rodrigues J.R. A fast inverse solver for the filtration function for flow of water with particles in porous media. // Inverse Problems, 2006, vol. 22, pp. 69-88.

11. Alvarez A.C., Hime G., Marchesin D., Bedrikovetsky P.G. The inverse problem of determining the filtration function and permeability reduction in flow of water with particles in porous media. // Transport in Porous Media, 2007, vol. 70(1), pp. 43-62.

12. Alvarez A.C., Hime G., Silva J.D., Marchesin D. Analytic regularization of an inverse filtration problem in porous media. // Inverse Problems, 2013, vol. 29, 025006.

13. Vyazmina E.A., Bedrikovetskii P.G., Polyanin A.D. New classes of exact solutions to nonlinear sets of equations in the theory of filtration and convective mass transfer. // Theoretical Foundations of Chemical Engineering, 2007, vol. 41(5), pp. 556-564.

14. Malgaresi G., Collins B., Alvaro P., Bedrikovetsky P. Explaining non-monotonic retention profiles during flow of sizedistributed colloids. // Chemical Engineering Journal, 2019, vol. 375, 121984. 
15. Altoe J.E., Bedrikovetsky P., Siqueira A.G., de Souza A.L.S., Shecaira F.S. Correction of basic equations for deep bed filtration with dispersion. // Journal of Petroleum Science and Engineering, 2006, vol. 51, pp. 68- 84.

16. Osipov Yu., Kotov N. Asymptotic model of size-exclusion grouting. // IOP Conference Series: Materials Science and Engineering, 2018, vol. 365, 042006.

17. Oliveira P., Vaz A., Siqueira F., Yang Y., You Z. Slow migration of mobilised fines during flow in reservoir rocks: Laboratory study. // Journal of Petroleum Science and Engineering, 2014, vol. 122, pp. 534-541.

18. Aji K., You Z., Badalyan A. Transport and straining of suspensions in porous media: experimental and theoretical study. // Thermal Science, 2012, vol. 16(5), pp. 1344-1348.

19. Badalyan A., You Z., Aji K., Bedrikovetsky P., Carageorgos T., Zeinijahromi A. Size exclusion deep bed filtration: Experimental and modelling uncertainties. // Review of scientific instruments, 2014, vol. 85(1), 015111.

20. Galaguz Y.P. Realization of the TVDscheme for a numerical solution of the filtration problem. // International Journal for Computational Civil and Structural Engineering, 2017, vol. 13(2), pp. 93-102.

21. Galaguz Y.P., Safina G.L. Modeling of fine migration in a porous medium. // MATEC Web of Conferences, 2016, vol. 86, 03003.
Liudmila I. Kuzmina, Candidate of Physical and Mathematical Sciences, Associate Professor, Department of Applied Mathematics, National Research University Higher School of Economics, 101000, Russia, Moscow, Myasnitskaya st., 20, tel. +7(495) $7729590 * 15219$, e-mail: lkuzmina@hse.ru.

Yuri V. Osipov, Candidate of Physical and Mathematical Sciences, Associate Professor, Department of Applied Mathematics, Moscow State University of Civil Engineering, 129337, Russia, Moscow, Yaroslavskoe Shosse, 26, tel. +7(499)1835994, e-mail: yuri-osipov@mail.ru.
Кузьмина Людмила Ивановна, доцент, кандидат физико-математических наук, Департамент прикладной математики, Национальный исследовательский университет «Высшая школа экономики»; 101000, г. Москва, ул. Мясницкая, д. 20, тел. +7(495) $7729590 * 15219$; e-mail: lkuzmina@hse.ru.

Осипов Юрий Викторович, доцент, кандидат физикоматематических наук, кафедра прикладной математики Национального исследовательского Московского государственного строительного университета; 129337 , Россия, г. Москва, Ярославское шоссе, д. 26; тел. +7(499)1835994; E-mail: yuri-osipov@mail.ru. 